\title{
Study on Sustainable Development Highway Traffic
}

\author{
Li Hongjun \\ College of Road and Rail, Hubei Communications Technical College, Wuhan, China Zip Code: 430079
}

\begin{abstract}
The rapid development of road traffic has provided a driving force for socio-economic development. By analyzing the current status of highway transportation development and investment in environmental protection of highway transportation, it is concluded that only by coordinating the relationship between the development of highway transportation and environmental protection can sustainable highway transportation be realized. By analyzing the practice of highway transportation development, this paper concluded that sustainable transportation development can only be achieved by adhering to resource conservation, environmental protection and technological innovation.
\end{abstract}

\section{Introduction}

With the continuous development of economy, the development of highway transportation is facing new and greater challenges. How to do a good job of environmental protection will be the problem that the development of highway transportation needs to face. In order to realize the sustainable development of highway transportation, we must do a good job in resource conservation and environmental protection [1]. Following the law of scientific development and taking the road of resource-saving and environment-friendly development is the way to realize the sustainable road traffic.

\section{Current situation of road traffic development}

At the end of 2018, the total mileage of national roads was 4.8465 million kilometers, an increase of 73100 kilometers over the previous year. The road density is $50.48 \mathrm{~km} / 100 \mathrm{~km} 2$, an increase of $0.76 \mathrm{~km} / 100 \mathrm{~km} 2$. The road maintenance mileage is 4.7578 million kilometers, accounting for $98.2 \%$ of the total mileage. The mileage of class IV and above highways in China is 4.4659 million kilometers, an increase of 127300 kilometers over the previous year, accounting for $92.1 \%$ of the total mileage, an increase of 1.3 percentage points. The mileage of class II and above highways is 647800 kilometers, an increase of 25600 kilometers, accounting for $13.4 \%$ of the total mileage, an increase of 0.3 percentage points. The expressway mileage is 142600 $\mathrm{km}$, an increase of $6100 \mathrm{~km}$; the expressway lane mileage is $633300 \mathrm{~km}$, an increase of $29000 \mathrm{~km}$. The national highway mileage is 105500 kilometers, an increase of 3300 kilometers. See Table 1 for statistics of China's highway development in the past five years.
Table 1.Statistics of highway development.

\begin{tabular}{|c|c|c|}
\hline year & $\begin{array}{c}\text { Total mileage of } \\
\text { highway }(\mathbf{1 0 0 0 0} \mathbf{~ k m})\end{array}$ & $\begin{array}{c}\text { highway density } \\
\left(\mathbf{k m} / \mathbf{1 0 0 k m}^{\mathbf{2}}\right)\end{array}$ \\
\hline 2014 & 446.39 & 46.5 \\
\hline 2015 & 457.73 & 47.68 \\
\hline 2016 & 469.52 & 48.91 \\
\hline 2017 & 477.35 & 49.72 \\
\hline 2018 & 484.65 & 50.48 \\
\hline
\end{tabular}

Data source: Development Statistics Bulletin of transportation industry in 2018

\section{Sustainable development of highway transportation}

The sustainable development goal of highway transportation is to realize the coordinated development of highway transportation and economy, society, resources and environment. The sustainable development mode of highway transportation should be resourcesaving and environment-friendly oriented, and build the infrastructure network, road transportation scale, operation and management information architecture, so as to achieve the optimal use of resources in different scenarios.

\subsection{Environmental protection concept of highway transportation}

Environmental protection and sustainable development of highway traffic are regarded as a dynamic development subject[2]. The development of highway traffic needs to do a good job in environmental protection. How to follow the development law, innovate the development concept, change the development mode and solve the development problems is the problems that must be solved to realize the sustainable development of

\footnotetext{
* Corresponding author: Leehj2004@163.com
} 
highway transportation. The implementation of traffic science and technology demonstration project and science and technology and environmental protection demonstration road, and striving to create "two types" of traffic are the specific measures to realize the sustainable development of highway traffic. Only by firmly establishing the new concept of resource-saving and environment-friendly traffic development can we realize the development of resource-saving and environmentfriendly traffic. Put the concept of "application is the best" and "nature is the most beautiful" into the whole process of road traffic development. Further explore the road of resource-saving and environment-friendly transportation development.

Highway transportation vigorously strengthens the protection of ecological environment, continues to promote the construction of ecological civilization, and adheres to the pursuit of green development, circular development and low-carbon development of highway transportation. From 2014 to 2018, the total investment in highway traffic environmental protection continued to increase. See Table 2 for statistics of total investment in highway traffic environmental protection in recent 5 years.

Table 2. total investment in highway traffic environmental protection

\begin{tabular}{|c|c|c|}
\hline year & $\begin{array}{c}\text { Highway } \\
\text { environmental } \\
\text { protection } \\
\text { investment } \\
\text { (RMB 100 } \\
\text { million) }\end{array}$ & Growth rate (\%) \\
\hline 2014 & 139.5 & \\
\hline 2015 & 140.5 & $0.72 \%$ \\
\hline 2016 & 141.6 & $0.78 \%$ \\
\hline 2017 & 142.8 & $0.85 \%$ \\
\hline 2018 & 143.9 & $0.77 \%$ \\
\hline
\end{tabular}

Data source: Review on environmental protection of roads and waterways in transportation industry in 2018

\subsection{Environmental protection measures for highway traffic}

\subsubsection{Respect nature and use resources}

The only way for sustainable development of highway transportation is to improve the utilization rate of resources and reduce the load of environment. Only by respecting nature can we realize the harmony between road and nature. Through the method of green construction, the natural environment can be protected to the maximum extent.

We should make full use of the old roads in highway construction and reconstruction. By controlling the balance of excavation and filling, all the earth and stone works can be fully and effectively utilized. Through the technical and economic demonstration, the purpose of flexible use of highway engineering technical indicators in the development of highway traffic is realized. Through the innovation of highway design structure, the purpose of saving land and materials most effectively is realized. Through planning and design, the plane and longitudinal layout of the route is reasonable, so as to reduce the excavation of mountains. The abandoned roads can be designed as viewing corridors, maintenance work areas and parking rest areas.

\subsubsection{Pay attention to the protection of natural resources}

The development of road traffic will have a major impact on the ecology, including barrier effect, proximity effect, ecological damage and pollution. The development of road traffic will occupy land, resulting in the cutting of rare wild plants. Effective measures must be taken to avoid the loss of plant resources in the development of highway transportation [3]. For example, deep or high subgrade will be replaced by tunnel or bridge. The rare plants should be avoided or transplanted. Plant trees at the road boundary or adjacent areas of the road.

\subsubsection{Green construction effectively protects the environment}

The green construction of highway traffic construction is realized by scientific construction organization plan, careful balance analysis of filling and excavation, reasonable allocation of earthwork and other methods [4]. Through a series of prevention, protection and control measures, the adverse impact and damage to the environment in the road traffic construction will be minimized. In the case of scarce land resources and precious topsoil in mountainous areas, the highway traffic construction should treasure the topsoil resources and make rational use of them. Waste slag must be utilized in highway traffic construction. The flat borrow area and spoil area can be used as the homestead or good farmland for local people. The construction access road can be trimmed to provide convenience for rural roads for people to travel.

\subsubsection{Prevention and control of environmental pollution}

The development of highway traffic has made great contribution to the improvement of traffic environment and the economic construction of the region. However, the development of road traffic inevitably has a direct or indirect impact on the natural ecological environment, and brings a series of environmental pollution problems. With the deep understanding of environmental protection, people put forward higher requirements for the development of highway traffic. The development of highway traffic should meet the requirements of landscape coordination and ecological environmental protection. The water quality pollution, air pollution and soil pollution during the road traffic operation period will also destroy the habitat of living creatures, worsen the living environment quality of animals and plants, cause large-scale migration of creatures, and destroy the 
original ecological balance [5]. Based on the characteristics and practice of the project area, various environmental protection measures shall be formulated and implemented scientifically. Through the local prevention and control, the whole line prevention and control, single prevention and comprehensive prevention and control measures, the discharge of various pollutants in the highway traffic project has reached the standard requirements. The sound produced by road traffic has become a long-term source of noise pollution. These noises include the noise caused by the friction between the wheels of the motor vehicle and the road surface, the horn sound of the vehicle driving and the vibration sound caused by the vehicle driving. Planting trees on both sides of the road is an effective measure to prevent traffic noise. The construction of noise barrier in the road section where the village residents are concentrated can prevent and control the noise pollution. These sound barriers include sound insulation wall, sound insulation tree belt or non noise sensitive buildings.

The main sources of air pollution in road traffic are vehicle exhaust and dust. In particular, a large amount of dust is raised by highway transportation, which not only affects the harvest of crops and fruit trees along the line, but also directly threatens the health of the people along the line. The road traffic management shall strictly implement the vehicle emission inspection system, and restrict the vehicles with excessive exhaust emissions on the road. In the long tunnel, the number of fans to be opened should be determined according to the traffic flow to meet the requirements of ventilation.

Strict environmental protection and water and soil conservation scheme review system shall be implemented for highway transportation projects. Through the construction of sedimentation tank at the construction site, the sewage treatment during the project construction shall be done well. It is only allowed to discharge the sewage after the treatment reaches the standard. The domestic sewage produced in the service area and management of highway traffic project shall be discharged after being treated by the sewage treatment facilities set up in a centralized way and reaching the standard.

There is no special waste disposal site for the waste materials produced by road traffic maintenance. A lot of maintenance waste materials are discarded at will. These waste materials not only occupy land, but also cause long-term environmental pollution. The highway traffic maintenance department shall collect, transfer and dispose the wastes in time.

\section{Sustainable development and change of highway transportation}

It is necessary to run resource conservation and environmental protection through the whole process of road traffic development to realize the sustainable development of road traffic. With the completion of highway transportation network, the research on highway transportation environment protection mainly focuses on the impact of highway transportation network on the environment. The impact of road traffic network on ecological environment is extensive, long-term and cumulative. With the formation and densification of the road traffic network, the factors affecting the ecological environment will become more complex and changeable.

\section{Measures for sustainable development of highway transportation}

\subsection{Improve the supervision mechanism}

The environmental protection management of highway traffic is under the responsibility of the government. Highway management departments at all levels need to have departments specially responsible for highway traffic environmental protection management. Highway traffic managers further improve the capacity of highway traffic environmental protection supervision by setting up a professional highway traffic environmental protection management organization and improving the management system and mechanism. Through special inspection, environmental protection acceptance and other means, the environmental protection management of highway traffic shall be implemented.

\subsection{Construction of monitoring network}

The highway traffic management department should systematically monitor the road environment. Highway traffic environmental monitoring can provide enough support for the development of highway traffic environmental protection. Through the establishment of highway traffic environment monitoring network platform and highway traffic environmental protection survey and statistics platform, the highway traffic environmental protection monitoring network is formed. This monitoring network can collect the data of highway traffic environment protection. The collected data can provide help for scientific decision-making and effective supervision.

\subsection{Pay attention to regional ecological security}

The development of highway traffic will have a longterm and complex impact on the ecological environment. The road traffic network will affect the wildlife population. Therefore, from the perspective of regional ecological security, we need to pay attention to the longterm cumulative effect of road traffic development to ensure regional ecological security. The development of highway transportation needs to adhere to the unity of development speed, structure and quality. Comprehensively promote the sustainable transportation development mode supported by scientific and technological innovation and characterized by green and low-carbon transportation. 


\subsection{Strengthening scientific research}

Correct decision-making must be based on relevant scientific research. The development of highway transportation needs to be studied in the direction of environmental protection of highway transportation in the whole life cycle. The research plan shall be specially listed for the implementation of highway traffic environmental protection. Through the research on the influence of road traffic network on water area, water source, human landscape, animals and plants, it can provide support for the development of road traffic.

\section{Conclusion}

The research on sustainable development of highway transportation is a long-term work. Highway traffic management departments should play the role of supervision and management of highway traffic environmental protection. Road traffic development must adhere to resource conservation, environmental protection and scientific and technological innovation. The development of highway transportation needs to exchange low cost of resources and environment for high speed of highway development. The sustainable development of highway transportation is to fundamentally improve the quality and efficiency of highway transportation economic growth. The sustainable development of highway traffic can be realized through the unity of economic benefits, social benefits and environmental benefits.

\section{References}

1. B.Huang, Mountain general environmental protection measures in highway construction, Technology of Highway and Transport, 4: 154158(2006)

2. X.X.Ning,Z.H.Liu,mountain highway construction the choice of indicators of environmental impact assessment and application, Highway, 4: 134-137 (2010)

3. S.F.Deng, expressway environmental protection countermeasures, Guangxi Communication Science \& Technology, 28: 97-99(2003)

4. G.Tong, Study on evaluation indexes and methods of sustainable development of highway transportation, Traffic standardization, 42: 102104(2014)

5. L.L.Yu,S.C.Li,H.L.Sun, Effects of Tunnel projecton Ecological Enviroment and Ecological Strategies,Bulletion of Soiland Water Conservation, 4:233-236(2010) 